Research Article

\title{
Novel Silver Nanoparticles Synthesized from Anthers of Couroupita Guianensis Abul. Control Growth and Biofilm Formation in Human Pathogenic Bacteria
}

\author{
Tahira Akther, Mohd Shahanbaj Khan, Hemalatha Srinivasan \\ B. S. Abdur Rahman Crescent Institute of Science and Technology, Chennai, India. \\ \Corresponding author. E-mail: hemalatha.sls@crescent.education
}

Received: May 30, 2018; Accepted: Jul. 19, 2018; Published: Aug. 21, 2018.

Citation: Tahira Akther, Mohd Shahanbaj Khan, Hemalatha Srinivasan, Novel Silver Nanoparticles Synthesized from Anthers of Couroupita Guianensis Abul. Control Growth and Biofilm Formation in Human Pathogenic Bacteria. Nano Biomed. Eng., 2018, 10(3): 250-257.

DOI: 10.5101/nbe.v10i3.p250-257.

\begin{abstract}
Couroupita guianensis (C. guianensis) Aubl. is an important medicinal plant utilized from ancient time for the treatment of various diseases. Different parts of the plant including root, stem, leaves, flower and fruit are exploited for their anti-inflammatory, anti-oxidative, anti-cardiac, antidiabetic, antibacterial and anticancer activities. In the present study, anther extract was utilized for cost effective and rapid synthesis of anther silver nanoparticles (A-AgNPs). The synthesis of silver nanoparticles was initially confirmed by surface plasmon resonance vibration with ultraviolet-visible spectroscopy (UV-Vis). Fourier-transform infrared spectroscopy (FTIR) analysis supported the capping and stability of A-AgNPs due to the presence of biomolecules in the extract. High-resolution transmission electron microscopy (HR-TEM) and scanning electron microscopy (SEM) analysis showed the synthesis of spherical, monodispersed and aggregated A-AgNPs and energy dispersive X-ray analysis (EDXA) confirmed the presence of silver. The efficacy of the A-AgNPs was screened against human bacterial pathogens (gram positive and gram negative), showing significant growth inhibition and biofilm formation. The results demonstrated that anthers of $C$. guianensis is a potent biosource for green synthesis of stable and reproducible silver nanoparticles and can be utilized as an alternative, cost-effective and potent alternative to antibiotics.
\end{abstract}

Keywords: C. guianensis; A-AgNPs; Biofilm; EDAX; FTIR; HR-TEM; SEM; Pathogenic bacteria

\section{Introduction}

Nanotechnology emerged as a multidisciplinary research area especially in the field of biomedical sciences $[1,2]$. Silver nanoparticles (AgNPs) among the several metal nanoparticles, have gained considerable attraction because of their unique properties including capping and stability, catalytic activity, antibacterial, antifungal, anticancer activities and so on [3]. Silver is an innoxious, nontoxic, inorganic, antimicrobial metallic compound that is efficient of killing about 650 types of microorganisms causing various diseases $[4,5]$. Silver nanoparticles are synthesized via physical, chemical and biological means. Green synthesis of silver nanoparticles especially using bacteria, fungi and plants has gained a great importance in recent years, because it is ecofriendly, simple, cost-effective, of stable nature and can be easily scaled up for large scale synthesis. Silver in the form of nanoparticles could be more reactive 
than their metallic form, due to their large surface area, and their ability to kill bacteria by penetrating into the cell membranes, leading to the accumulation of intracellular nanoparticles that cause disruption of cell and effectively inhibit the microbial growth [6]. AgNPs have been reported to be very effective against various bacteria, viruses, fungi and other eukaryotic microorganisms at very low concentrations [7].

Couroupita guianensis (C. guianensis) belongs to the family Lecythidaceae, commonly known as cannon ball, and is widely used as medicine to treat various diseases such as asthma, hypertension, tumours, pain, and inflammation [8].

The present study aims to biosynthesize silver nanoparticles from anther extract of C. guianensis, and characterize, by biophysical methods, the bactericidal potential of A-AgNPs against gram negative and gram positive bacterial strains.

\section{Experimental}

\section{Preparation of flower extract}

C. guianensis flowers were collected from the campus of B.S. Abdur Rahman Crescent Institute of Science and Technology, Chennai. The samples were washed thoroughly with distilled water to remove extraneous materials. $5 \mathrm{~g}$ of the anthers were finely cut into small pieces and stirred with $100 \mathrm{~mL}$ sterile distilled water for $1 \mathrm{~min}$ and kept in a water bath at $60{ }^{\circ} \mathrm{C}$ for 15 min. Finally, the extract was filtered in hot condition with Whatman No. 1 filter paper and used for further experiments [9].

\section{Biosynthesis and characterization of AgNPs}

For the biosynthesis of AgNPs, flower anther extract was mixed with $1 \mathrm{mM} \mathrm{AgNO}_{3}$ solution at 1:1 ratio, stirred well for $1 \mathrm{~min}$ and incubated in dark at room temperature under static condition. A control was also maintained without anther extract [10]. The bioreduction of $\mathrm{AgNO}_{3}$ into AgNPs was periodically monitored using ultraviolet-visible spectrophotometer in the range of $300 \sim 700 \mathrm{~nm}$ absorption wavelengths. After $48 \mathrm{~h}$ of reaction, the mixture was centrifuged at $15,000 \mathrm{rpm}$ for $20 \mathrm{~min}$ at $4{ }^{\circ} \mathrm{C}$. The resulting pellet was resuspended in sterile distilled water for washing and freeze drying. The freeze dried AgNPs were then characterized by using ultraviolet-visible spectroscopy (UV-Vis), high resolution transmission electron microscopy (HR-TEM), scanning electron microscopy (SEM), and energy dispersive X-ray analysis (EDXA) techniques. Fourier transform infrared spectroscopy (FTIR) was carried out to identify the presence of potential biomolecules in C. guianensis extract. FTIR spectrum was recorded at a Perkin Elmer Spectrum100, in the wavelength range of $4000 \sim 400 / \mathrm{cm}$.

\section{Antibacterial efficacy of AgNPs}

AgNPs were examined for their inhibitory activity against six bacterial strains such as Escherichia coli (ATCC 25922), Salmonella typhimurium (ATCC 14028), Pseudomonas aeruginosa (ATCC 27853), Acinetobacter baumannii (ATCC 19606), Proteus mirabilis (ATCC 35659) and Methicillin resistant Staphylococcus aureus (MRSA) by well diffusion method [11]. ATCC bacterial strains were purchased from the American Type Culture Collection. A suspension of $12 \mathrm{~h}$-old bacterial culture was swabbed on nutrient agar plates using sterile cotton swabs. In each well, $20 \mu \mathrm{L}$ of the nanoparticle suspension $(1 \mathrm{mg} /$ $\mathrm{mL}$ ) was loaded on nutrient agar plates aseptically. The plates were incubated at $37^{\circ} \mathrm{C}$ for $24 \mathrm{~h}$, and the diameter of zone of inhibition was measured.

\section{Biofilm formation assay}

Biofilm formation was carried out using 96well microplate [12]. An overnight bacterial culture of Escherichia coli (ATCC 25922), Salmonella typhimurium (ATCC 14028), Pseudomonas aeruginosa (ATCC 27853), Acinetobacter baumannii (ATCC 19606), Proteus mirabilis (ATCC 35659) and MRSA were diluted into fresh medium for performing this assay. Briefly, A-AgNPs were serially diluted with luria broth (LB) to prepare a series of different dilutions. 10 $\mu \mathrm{L}$ culture of different species of bacteria was added to each well and incubated for $12 \sim 24 \mathrm{~h}$ at $37{ }^{\circ} \mathrm{C}$. After incubation, the planktonic bacterial cells were removed with water, $125 \mu \mathrm{L}$ of $0.1 \%$ crystal violet was added to all the wells, and the plate was incubated for $10 \sim$ $15 \mathrm{~min}$ at room temperature. The plate was later rinsed with distilled water and dried. $125 \mu \mathrm{L}$ of $30 \%$ acetic acid was added to solubilized crystal violet. Acetic acid was allowed to sit for $10 \mathrm{~min}$. The absorbance was measured at $517 \mathrm{~nm}$ using a microplate reader to quantify the biofilm formation.

\section{Minimum inhibitory concentration (MIC) and minimum bactericidal concentration (MBC)}

The antimicrobial potency of A-AgNPs was determined by broth dilution method [13]. The MIC was examined in LB broth using serial dilution of silver nanoparticles in 96 well plates. Bacterial culture 
without A-AgNPs was kept as positive control, and both without culture and A-AgNPs was kept as negative control. 96 well plates were incubated for $24 \mathrm{~h}$ at $37^{\circ} \mathrm{C}$. $99 \%$ visual growth inhibition of microorganism by the lowest concentration of antibiotic is known as MIC. The MIC of A-AgNPs was noted before and after incubation by the visual turbidity of the 96 well plates to confirm its value for all the six bacterial strains.

After the MIC was recorded of the A-AgNPs, aliquots of $10 \mu \mathrm{L}$ from all the wells which showed no turbid visible growth were inoculated in LB agar plates without A-AgNPs at $37{ }^{\circ} \mathrm{C}$ for $24 \mathrm{~h}$. Before and after incubation of agar plates, MBC was observed for presence and absence of bacterial growth. $99.9 \%$ of the bacterial population was killed by the lowest concentration of antibiotic, which is known as MBC.

\section{Results and Discussion Characterization of A-AgNPs}

The colour change in the C. guianensis anther aqueous extract was observed when mixed with silver nitrate. Absorption spectrum revealed a peak at 418 $\mathrm{nm}$, confirming the reduction of silver nitrate to silver nanoparticles (Fig. 1). The colour change was observed within 15 min from light brown to dark brown. Silver nitrate without extract was kept as control and no colour change was observed.

It has been reported that terpenoids or alkaloids present in the plant extract act as reducing and capping

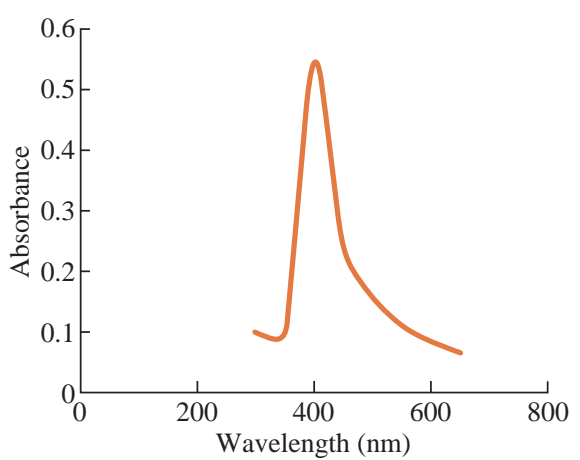

Fig. 1 UV-Vis spectra of A-AgNPs synthesized from $C$. guianensis anther extract.

source of silver nanoparticles and provide stability to AgNPs [14]. Phytochemicals such as terpenoids, flavonoids, ketones, aldehydes, amides and carboxylic acids are responsible for the bioreduction of silver ions and formation of silver nanoparticles [15]. Surface plasmon resonance band in silver nanoparticles remained close to $418 \mathrm{~nm}$, which indicated the formation of silver nanoparticles. Earlier studies showed that surface plasmon band at around $300 \sim 500$ $\mathrm{nm}$ was a characteristic feature of silver nanoparticles [16]. Silver nanoparticles capped with aqueous anther extract showed maximum absorption at $418 \mathrm{~nm}$, which was in agreement with earlier studies [17].

The FTIR analysis of A-AgNPs showed the presence of different stretches and various functional groups including alkanes, alkynes, nitriles and carboxyl groups (Fig. 2, Table 1).

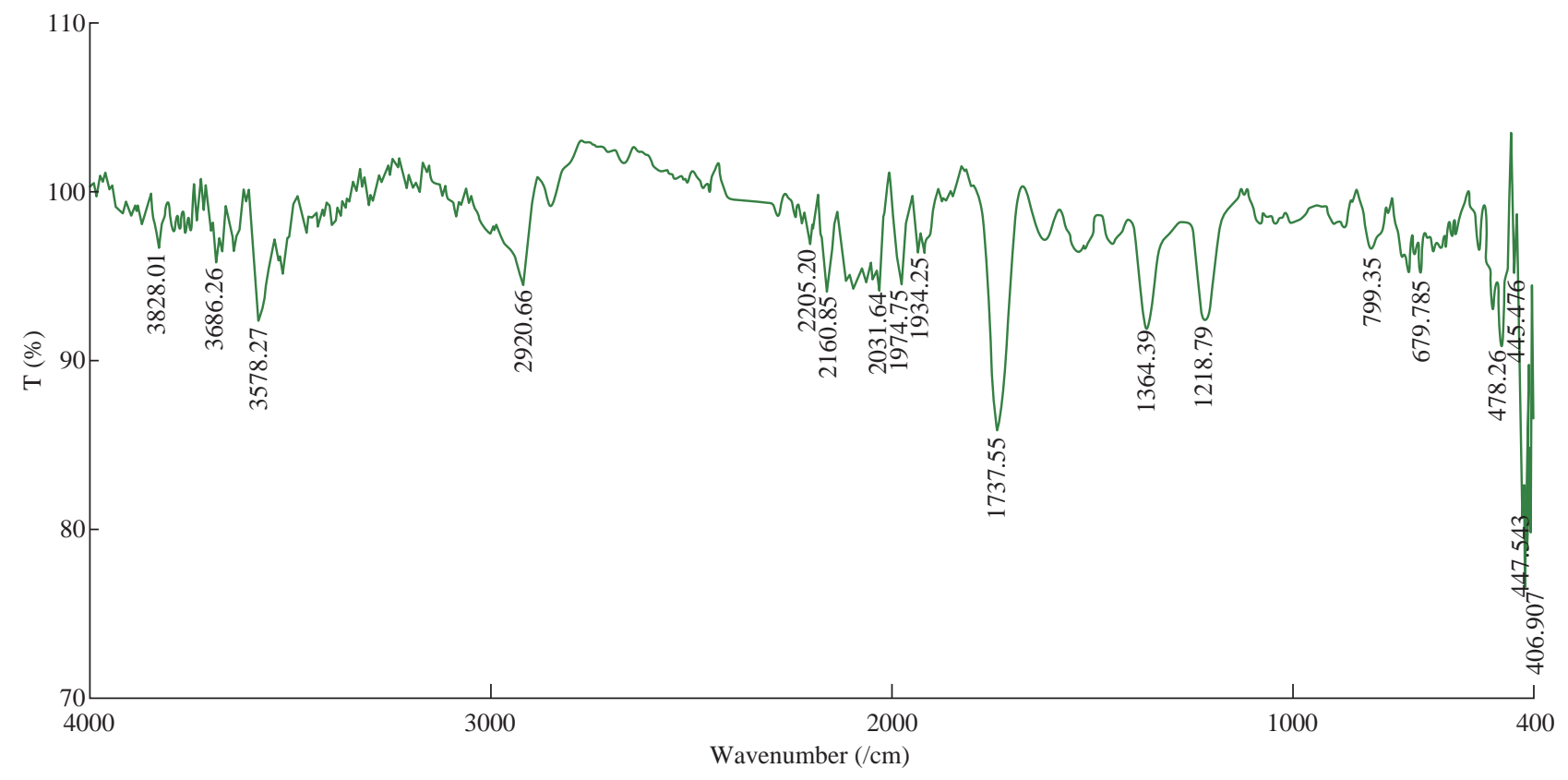

Fig. 2 FTIR spectra of A-AgNPs synthesized from C. guianensis anther extract. 
Table 1 Different peaks of FTIR spectra of A-AgNPs showing the different bonds and functional groups

\begin{tabular}{ccc}
\hline Frequency $(/ \mathrm{cm})$ & Bond & Functional group \\
\hline 2920.66 & $\mathrm{C}-\mathrm{H}$ stretch & Alkanes \\
2205.2 & $\mathrm{C} \equiv \mathrm{N}$ stretch & Nitriles \\
2160.85 & $-\mathrm{C} \equiv \mathrm{C}-$ stretch & Alkynes \\
1737.55 & $\mathrm{C}=\mathrm{O}$ stretch & Carbonyl (General) \\
$1370-1350$ & $\mathrm{C}-\mathrm{H}$ rock & Alkanes \\
1218.79 & $\mathrm{C}-\mathrm{N}$ stretch & Aliphatic amines \\
799.35 & $=\mathrm{C}-\mathrm{H}$ stretch & Alkenes \\
676.785 & $-\mathrm{C} \equiv \mathrm{C}-\mathrm{H}: \mathrm{C}-\mathrm{H}$ bend & Alkynes \\
\hline
\end{tabular}

In our earlier findings, we reported that $C$. guianensis was rich in flavonoids and phenols [18]. FTIR analysis of flower extract of C. guianensis showed the presence of various functional groups including phenols, flavonoids, stigma sterol and aliphatic hydrocarbons $[19,20]$.

Phenolic compounds possess the ability to reduce silver ions $\mathrm{Ag}^{+}$to free nano size silver $\left(\mathrm{Ag}^{0}\right)$ due to its electron donating property [21]. In the present study, FTIR analysis showed the presence of nitrile and carboxyl groups that could bind with heavy metals. The presence of these functional groups suggested that A-AgNPs were stable due to the presence of these functional groups.

Morphology, size, shape and purity of silver nanoparticles were investigated by TEM, SEM and

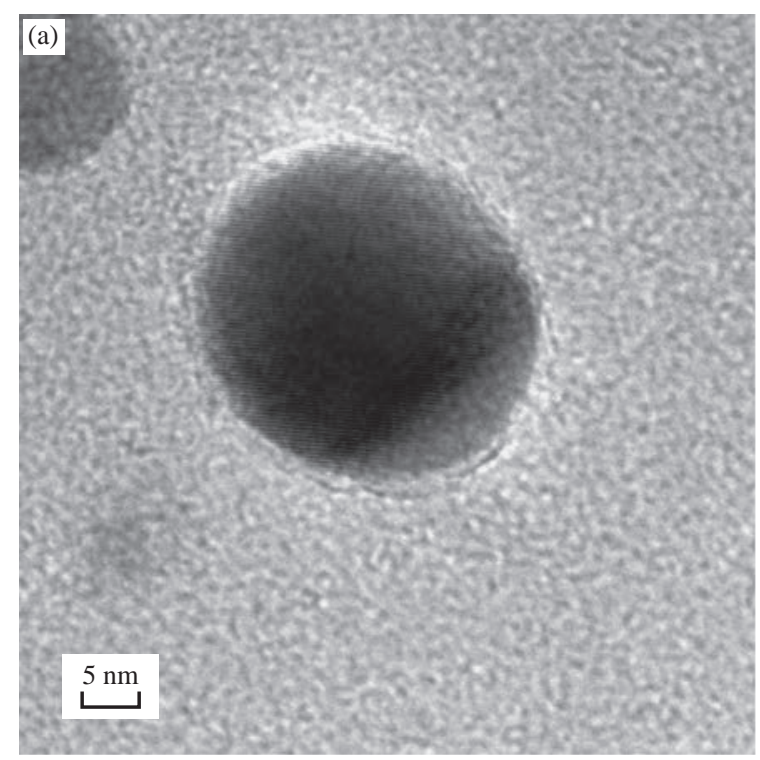

EDXA. A-AgNPs showed spherical shape and polydispersed in TEM micrograph at 5 to $100 \mathrm{~nm}$ scale. The particle size distribution of A-AgNPs showed the average range of particle size between $0.5 \sim 10 \mu \mathrm{m}$ (Fig. 3 (a)-(b)).

SEM analysis showed high-density silver nanoparticles synthesised by using aqueous anther extract. Silver nanoparticles were revealed spherical in shape with aggregation of small silver nanoparticles with an average range of $10 \sim 50 \mu \mathrm{m}$ diameter (Fig. 4(a)-(b)). The obtained size distribution was found to be similar in TEM.

Silver nanoparticles were not monodisperse in nature. Elemental composition of synthesized nanoparticles were analysed with EDXA and revealed the presence of carbon $(\mathrm{C})$, oxygen $\left(\mathrm{O}_{2}\right)$ and potassium (K) along with very small quantity of silver (Ag) (Fig. 5).

The present investigation was in agreement with earlier reports [22] where AgNPs synthesized from leaf and fruit extract of $C$. guianensis showed a plasmon resonance at $420 \mathrm{~nm}$ in UV-Vis. TEM and SEM analysis revealed the size of AgNPs ranging between $10 \sim 45$ and $5 \sim 15 \mathrm{~nm}$. This supported our findings and suggested AgNPs synthesized from anther extract of $C$. guianensis have spherical shape and stabilized due to surface plasmon resonance.

\section{Antibacterial efficacy of A-AgNPs}

The antibacterial potential of A-AgNPs was evaluated by agar well diffusion method using

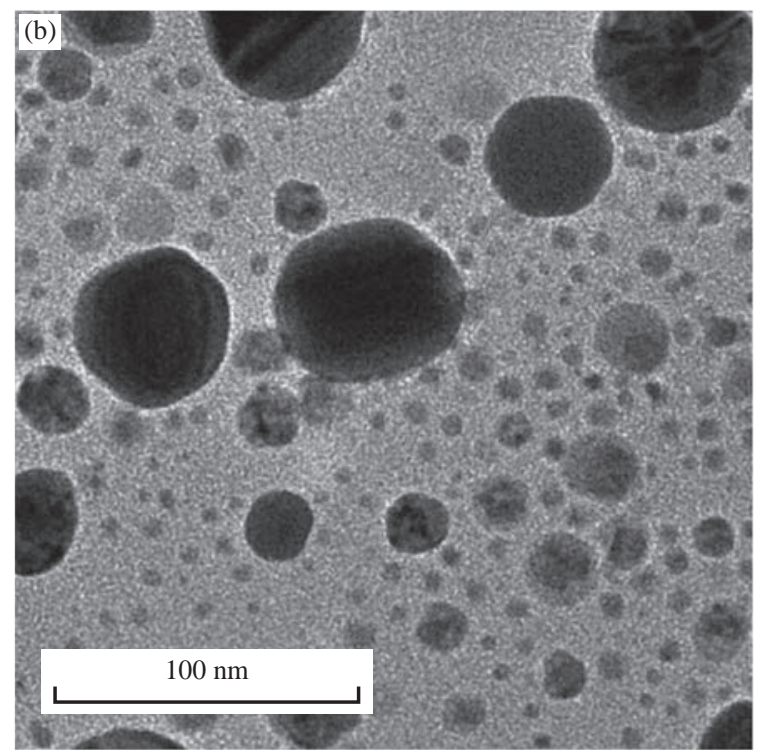

Fig. 3 HR-TEM micrographs of A-AgNPs synthesized from C. guianensis anther extract. (a) Single nanoparticle at $5 \mathrm{~nm}$ scale; (b) Scattered nanoparticles at $100 \mathrm{~nm}$ scale. 

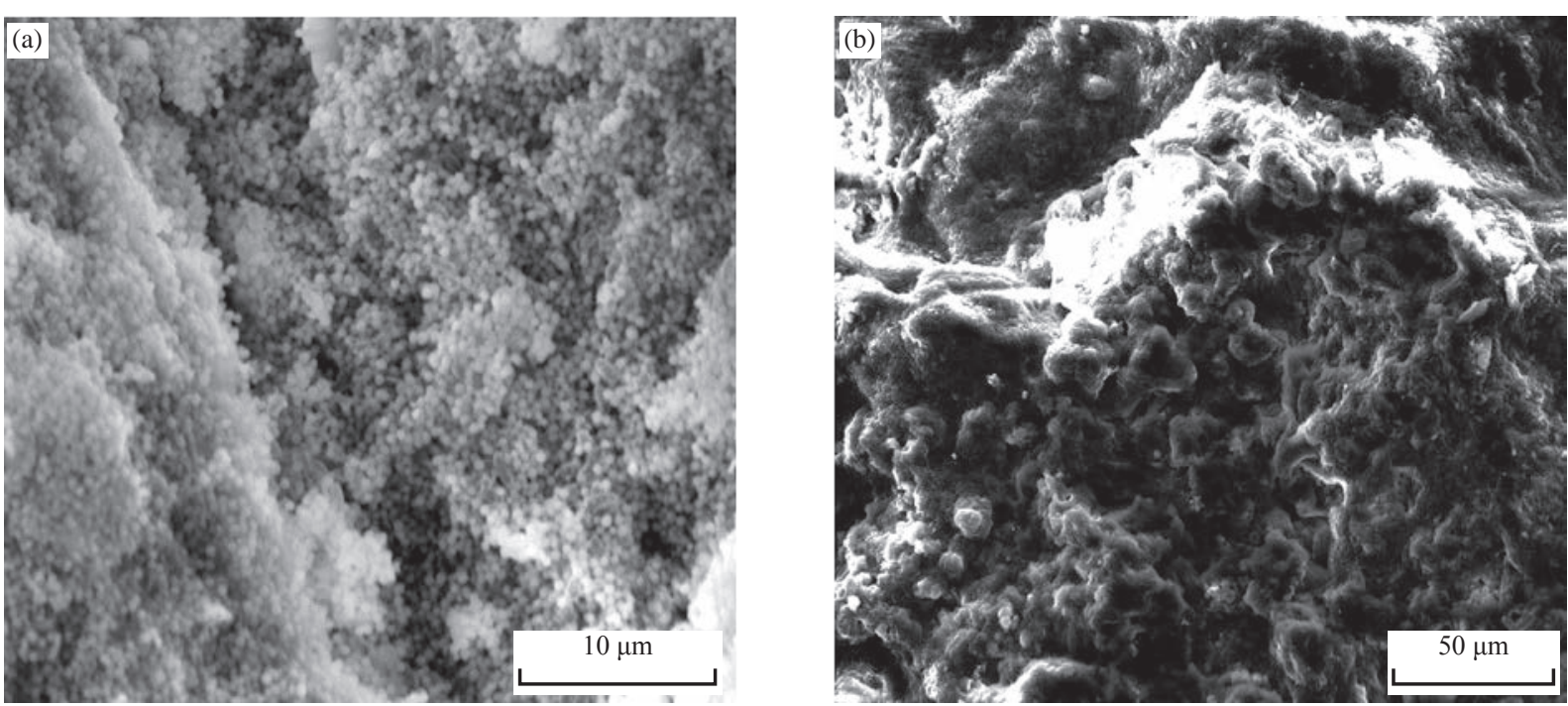

Fig. 4 SEM micrographs of A-AgNPs synthesized from C. guianensis anther extract. (a) Particle size at $10 \mu \mathrm{m}$ scale; (b) Particle size at $50 \mu \mathrm{m}$ scale.

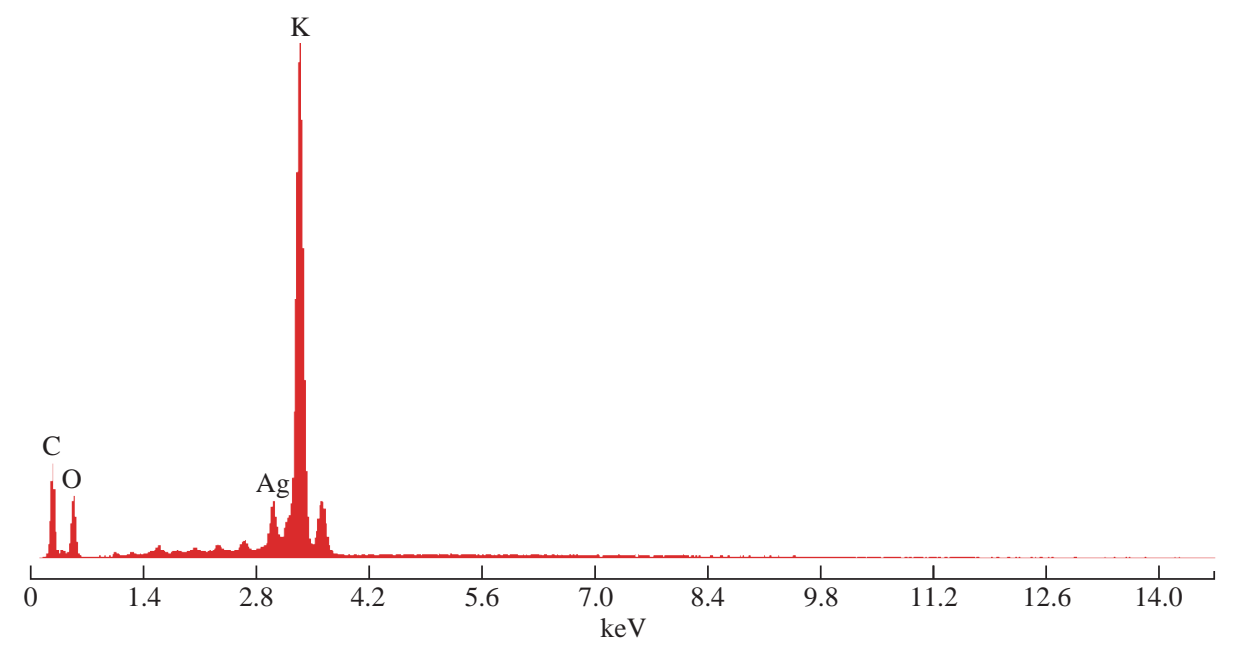

Fig. 5 EDXA result of A-AgNPs synthesized from C. guianensis anther extract.

antibiotic ampicillin as standard. The A-AgNPs were screened against both gram negative and gram positive bacterial strains (Pseudomonas aeruginosa, Salmonella typhimurium, Proteus. mirabilis, Acinetobacter baumannii, MRSA and Escherichia coli). The zone of inhibition against gram positive and negative bacteria is shown in Fig. 6.

The A-AgNPs showed significant zone of inhibition, and the maximum inhibition zone $(45 \mathrm{~mm})$ was observed against MRSA followed by $35 \mathrm{~mm}$ in A. baumannii. The A-AgNPs were revealed to inhibit the growth of all the organism tested when compared to the antibiotic standard.

Although silver is used as an antimicrobial agent for many years, the exact mechanism to inhibit the bacterial growth is still not well known. Many possibilities have been predicted in the literature

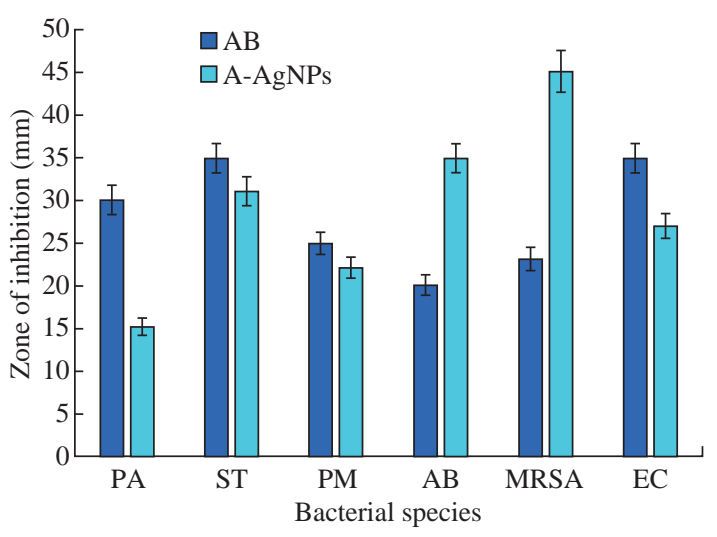

Fig. 6 Zone of inhibition in different human pathogenic bacterial isolates treated with A-AgNPs and antibiotics (AB). PA $=P$. aeruginosa $; S T=S$. typhimurium $; \mathrm{PM}=P$. mirabilis; $\mathrm{AB}$ = A. baumannii; MRSA = Methicillin resistant Staphylococcus aureus; $\mathrm{EC}=$ E. coli.

including disruption of proton gradient pump on cell membrane [23], inhibition of cell division, DNA 
unwinding, disruption of cell wall, that may lead to cell death $[24,25]$.The inhibitory effect against bacterial species is due the presence of phenols, flavonoids, aromatic compounds, isatin and indirubin in flower buds of $C$. guianensis.

Earlier stigmasterol and quercetin were isolated from flower of C. guianensis supported the antibacterial efficacy [26]. Quercetin is an important class of flavonoids reported to inhibit the E. coli DNA gyrase B by blocking adenosine triphosphate (ATP) binding site and induced the DNA damage [27, 28]. The flavonoid quercetin also enhanced the bacterial membrane permeability and loss of membrane potential. Our results suggested that the presence of different compounds and their different modes of action in extract were responsible for bacterial inhibition.

The phytochemical constituents present in the anther that helped in the reduction of silver nanoparticles and these nanoparticles could have diffused through the medium and effectively inhibited the growth of all bacteria and especially effective on A. baumannii.

\section{Biofilm quantification}

The biofilm formation was inhibited by A-AgNps in all the ATCC strains of $P$. aeruginosa, $S$. typhimurium, $P$. mirabilis, A. baumannii, MRSA and E. coli. A-AgNPs inhibited biofilm formation in all the bacterial strains when compared to control and antibiotic treatment (Fig. 7).

The results suggested that the inhibition of biofilm formation by A-AgNPs might be due to the presence of flavonoids, phenols and carboxylic compounds. It has been reported that Melaleuca alternifolia plant extract inhibited the biofilm formation by damaging the bacterial membrane structure [29]. Earlier reports suggested that flavonoids present in plant extract

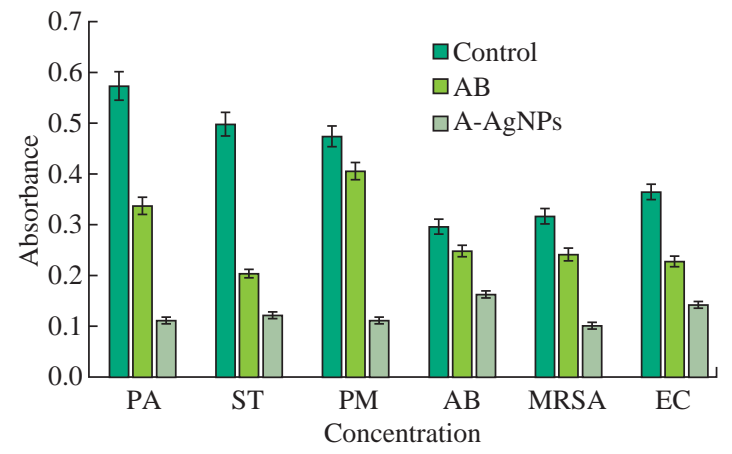

Fig. 7 The biofilm inhibition in different human pathogenic bacteria treated with A-AgNPs, antibiotics $(\mathrm{AB})$ as standard and no treatment as control. $\mathrm{PA}=P$. aeruginosa; $S T=S$. typhimurium; $\mathrm{PM}=$ P. mirabilis; $\mathrm{AB}=$ A. baumannii; $\mathrm{MRSA}=$ Methicillin resistant Staphylococcus aureus; $\mathrm{EC}=$ E. coli.

inhibited the biofilm production of bacteria by disrupting quorum sensing [30].

\section{Minimum inhibitory and bactericidal concentrations}

In the present study, MIC and MBC of anther silver nanoparticles against $P$. aeruginosa, $S$. typhimurium, P. mirabilis, A. baumannii, MRSA and E. coli were evaluated (Table 2).

The A-AgNPs showed highest MIC in MRSA as of $7.8 \mu \mathrm{g} / \mathrm{mL}$, followed by A. baumannii and $S$. typhimurium $15.6 \mu \mathrm{g} / \mathrm{mL}$, E. coli, P. aeruginosa $31.2 \mu \mathrm{g} / \mathrm{mL}$, and P. mirabilis $62.5 \mu \mathrm{g} / \mathrm{mL}$ (Table 2). Similarly, the minimal bactericidal concentration was also observed in MRSA as of $15.6 \mu \mathrm{g} / \mathrm{mL}$, followed by E.coli and A. baumannii, $31.2 \mu \mathrm{g} / \mathrm{mL}$ respectively (Table 2 ). The results suggested that due to spherical size and aggregation, A-AgNPs were able to penetrate the bacterial cell wall and inhibited the bacterial growth. Earlier study reported that the size of nanoparticles correlated with antimicrobial activity [31].

Table 2 MIC and MBC in different bacterial strains treated with A-AgNPs and antibiotics (AB) as standard

\begin{tabular}{|c|c|c|c|c|}
\hline Bacterial isolates & (AB) MIC $(\mu \mathrm{g} / \mathrm{mL})$ & (A-AgNPs) MIC $(\mu \mathrm{g} / \mathrm{mL})$ & (AB) $\mathrm{MBC}(\mu \mathrm{g} / \mathrm{mL})$ & (A-AgNPs) MBC $(\mu \mathrm{g} / \mathrm{mL})$ \\
\hline P. aeruginosa & 15.6 & 31.2 & 31.2 & 62.5 \\
\hline S. typhimurium & 15.6 & 15.6 & 31.2 & 62.5 \\
\hline P. mirabilis & 31.2 & 62.5 & 62.5 & 125 \\
\hline A. baumannii & 62.5 & 15.6 & 62.5 & 31.2 \\
\hline MRSA & 62.5 & 7.8 & 31.2 & 15.6 \\
\hline E.coli & 15.6 & 31.2 & 62.5 & 31.2 \\
\hline
\end{tabular}

Note: $\mathrm{MIC}=$ minimum inhibitory concentration; $\mathrm{MBC}=$ minimum bactericidal concentration . 


\section{Conclusions}

The nanoparticles synthesized from flower anther of C. guianensis showed the nanoparticle synthesis by reducing silver ions to nano silver under UV-Vis. FTIR revealed the presence of different biomolecules including phenols and flavonoids in anther extract that provided the surface plasmon resonance, capping and stability to synthesized nanoparticles. Different sizes and shapes of nanoparticles were verified with morphological analysis using HR-TEM and SEM, and the presence of silver verified by EDXA. The synthesized A-AgNPs showed a significant and potent antibacterial and anti-biofilm activity against gram positive and gram negative ATCC bacterial strains. The study confirmed that A-AgNPs had the potential to inhibit these human pathogenic isolates and could be utilized as an alternative and cost-effective source of antibioticsto inhibit human microbial pathogens. These A-AgNPs may be useful against antimicrobial resistance and be utilized for targeted drug delivery. We are the first to synthesize the silver nanoparticles from the anthers of $C$. guianensis and demonstrated its efficacy against the ATCC bacterial strains.

\section{Acknowledgements}

Tahira Akther and Mohd Shahanbaj Khan are thankful to B. S. Abdur Rahman Crescent Institute of Science and Technology, Chennai for providing Junior and Senior Research Fellowships and research facility to conduct the research.

\section{Conflict of Interest}

The authors declare that no conflict of interest

\section{References}

[1] K. Natarajan, S. Selvaraj, M.V. Ramachandra, et al., Microbial production of silver nanoparticles. Digest Journal of Nanomaterials and Biostructures, 2010, 5: 135-140.

[2] V. Gopinath, D. Mubarak-Ali, S. Priyadarshini, et al., Biosynthesis of silver nanoparticles from Tribulus terrestris and its antimicrobial activity: A novel biological approach. Colloids and Surfaces B: Biointerfaces, 2012, 96: 69-74.

[3] V.K. Sharma, R.A. Yngard, Y. Lin, et al., Silver nanoparticles: green synthesis their antimicrobial activities. Advances Colloid Interface Science, 2009, 145: 83-96.

[4] S.H. Jeong, S.Y. Yeo, S.C. Yi, et al., The effect of filler particle size on the antibacterial properties of compounded polymer/silver fibers. Journals of Materials Science, 2005, 40: 5407-5411.

[5] M. Rai, A. Yadav, A. Gade, et al., Silver nanoparticles as a new generation of antimicrobials. Biotechnology Advances, 2009, 27: 76-83.

[6] T.S. Dhas, V.G. Kumar, V. Karthick, et al., Facile synthesis of silver chloride nanoparticles using marine alga and its antibacterial efficacy. Spectrochimica Acta Part A: Molecular and Biomolecular Spectroscopy, 2014, 120: 416-420.

[7] J.R. Morones, J.L. Elechiguerra, A. Camacho, et al., The bactericidal effect of silver nanoparticles. Nanotechnology, 2005, 16: 2346-2353.

[8] J. Sanz-Biset, J. Campos-de-la-Cruz, M.A. EpiquiénRivera, et al., A first survey on the medicinal plants of the Chazuta valley (Peruvian Amazon). Journal of Ethnopharmacol, 2009, 122(2): 333-362.

[9] D.B. Pushkar, P.I. Sevak, Green synthesis of silver nanoparticles using Couroupita guianensis fruit pulp and its antibacterial properties. World Journal of Pharmaceutical Research, 2016, 5(9): 1174-1187.

[10] K. Roy, C.K. Sarkar, C.K. Ghosh, et al., Plantmediated synthesis of silver nanoparticles using parsley (Petroselinum crispum) leaf extract: spectral analysis of the particles and antibacterial study. Appl Nanosci, 2015, 5: 945-951.

[11] P. Nalawade, P. Mukherjee, S. Kapoor, et al., Biosynthesis, characterisation and antibacterial studies of silver nanoparticles using pods extract of Acacia auriculiformis. Spectrochimica Acta, Part A: Molecular and Biomolecular Spectroscopy, 2014, 129: 121-124, 204-211.

[12] R. Thenmozhi, P. Nithyanand, J. Rathna, et al., Antibiofilm activity of coral associated bacteria against different clinical Mserotypes of Streptococcus pyogenes. FEMS Immunology and Medical Microbiology, 2009, 57: 284-294.

[13] Clinical and Laboratory Standards Institute, Methods for dilution antimicrobial susceptibility tests for bacteria that grow aerobically. Approved standard. Clinical and Laboratory Standards Institute document M7-A7, 2006, $7^{\text {th }} \mathrm{Ed}$.

[14] M. Premanathan, S. Radhakrishan, K. Kulangiappar, et al., Antioxidant and anticancer activities of isatin (1H-indole-2,3-dione), isolated from the flowers of Couroupita guianensis Aubl. Indian Journal of Medical Research, 2012, 136(5): 822-826.

[15] K.J. Rao, S. Puria, Green synthesis of silver nanoparticles fromaqueous Aegle marmelosleaf extract. Material ResearchBulletin, 2013, 48: 628-634.

[16] N.A.A. Aziz, L.H. Ho, B. Azahari, et al., Chemical and functional properties of the native banana (Musa acuminata $\times$ balbisianaColla $\mathrm{cv}$. Awak) pseudo-stem and pseudo-stem tender core flours. Food Chemistry, 2011, 128: 748-753.

[17] R.R. Naik, S.J. Stringer, G. Agarwal, et al., Biomimetic synthesis and patterning of silver nanoparticles. Nature Materials, 2002, 1: 169-172.

[18] T. Akther, M.S. Khan, S. Hemalatha, et al., Extraction of flavonoid from various parts of Couroupita guianensis and its efficacy against pathogenic bacteria. Asian Journal of Pharmaceutical and Clinical Research, 2017, 10(4): 354-358.

[19] V. Prabhu, R.Subban, Quantification of quercetin and stigmasterol of Couroupita guianensis aubl by hptlc method and in vitro cytotoxic activity by mtt assay of the methanol extract against hela, nih $3 \mathrm{t} 3$ and hepg2 cancer cell lines. International Journal of Pharmaceutical Science, 2012, 4: 126-130.

[20] J.B. Rane, S.J. Vahanwala, S.G. Goltkar, et al., Phytochemical screening yielded flavonoids, like 
20,40-dihydroxy-60-methoxy-30, 50-dimethylchalcone,7hydroxy-5-methoxy-6,8-dimethylflavanone and the phenolic acid 4-hydroxybenzoic acid. Indian Journal Pharmaceutical Science, 2001, 63: 72-73.

[21] K.S. Siddiqi, A. Husen, R.A.K. Rao, et al., A review on biosynthesis of silver nanoparticles and their biocidal properties. Journal of Nanobiotechnology, 2018, 16: 14.

[22] R.T. Vimala, G.S. kumar, S.S. krishnan, et al., Optimization of reaction conditions to fabricate nanosilver using Couroupita guianensis Aubl. (leaf \& fruit) and its enhancedlarvicidal effect. Spectrochimica Acta PartA: Molecular and Biomolecular Spectroscopy, 2015, 25(135): 110-115.

[23] S.K. Sivaraman, I. Elango, S. Kumar, et al., A green protocol for room temperature synthesis of AgNPs in seconds. Current Science, 2009, 97: 1055-1059.

[24] S. Kumar, K. Sneha, S.W. Won, et al., Cinnamon zeylanicum bark extract and powder mediated green synthesis of nano-crystalline silver particles and its bactericidal activity. Colloids Surfaces B: Biointerfaces, 2009, 73: 332-338

[25] K.C. Wong, D.Y. Tie, Couroupita flowers yield an alipathic hydrocarbon and stigma sterol, alkaloids, phenolics and flavonoids, and has the active principles isatin and indirubin (vital to its antimicrobial activity). Journal of Essential Oil Research, 1995, 7: 225-227.

[26] V. Prabhu, R. Subban, Quantification of quercetin and stigma sterol of Couroupita guianensis aubl by hptlc method and in vitro cytotoxic activity by mtt assay of the methanol extract against hela, nih $3 \mathrm{t} 3$ and hepg2 cancer cell lines. International Journal of Pharmaceutical Science, 2012, 4: 126-130.
[27] A. Plaper, M. Golob, I. Hafner, et al., Characterization of quercetin binding site on DNA gyrase. Biochemical and Biophysical Research Communication, 2003, 306: 530536.

[28] O.K. Mirzoeva, R.N. Grishanin, P.C. Calder, et al., Antimicrobial action of propils and some of its components: the effects on growth, membrane potential and motility of bacteria. Microbiological Research, 1997. 152: 239-246.

[29] S.D. Cox, C.M. Mann, J.L. Markham, et al., The mode of antimicrobial action of the essential oil of Melaleuca alternifolia (tea tree oil). Journal of Applied Microbiology, 2000, 88: 170-175.

[30] S. Manner, M. Skogman, D. Goeres, et al., Systematic exploration of natural and synthetic flavonoids for the inhibition of Staphylococcus aureus biofilm. International Journal of Molecular Sciences, 2013, 14: 19434-19451.

[31] S. Pal, Y.K. Tak, J.M. Song, et al., Does the antibacterial activity of silver nanoparticles depend on the shape of the nanoparticle? A study of the gram-negative bacterium Escherichia coli. Applied and Environmental Microbiology, 2007, 73: 1712-1720.

Copyright $(\subset$ Tahira Akther, Mohd Shahanbaj Khan, and Hemalatha Srinivasan. This is an open-access article distributed under the terms of the Creative Commons Attribution License, which permits unrestricted use, distribution, and reproduction in any medium, provided the original author and source are credited. 